\title{
The Modification of Cigarette Smoke by Filter Tips*
}

by J. T. Williamson, J. F. Graham, D. R. Allman

Cigarette Components Ltd., London

In considering the factors which determine the composition of tobacco smoke, it is acknowledged that one of the major influences is the effect of the use of filters on cigarettes. In earlier days it was widely but erroneously held that filters had a very limited effect on the composition of tobacco smoke, and that in fact they tended to remove a uniform quantity of everything from the smoke.

In recent years, however, it has become more generally realized that filters can have a selective effect on smoke, that is that the percentage removal of all the constituents need not be the same for any one cigarette filter combination. Hoffmann and Wynder (1) for example, demonstrated that the percentage of phenol removed by a cellulose acetate filter containing certain additives was much greater than the percentage of nicotine removed by the same filter at the same time. Others $(2,3,4,5)$ have demonstrated the effect of the use of adsorbent additives in filters, which again causes selective removal of a different range of compounds. As this field of investigation is of particular interest to us we have spent a considerable amount of time investigating suitable methods for studying the selective action of filters and we shall review here some of the results obtained.

In the first part of the paper we have used modifications of standard methods to determine chemically and spectrophotometrically the efficiencies of a range of filters towards each of five specific compounds in the smoke (Figure 1), whose boiling points are widely distributed over the range of smoke constituents.

However, there are a very large number of compounds in tobacco smoke and to devise and carry out specific tests for large numbers of these for every filter tested would be an enormous task. The second part of the paper deals, therefore, with a chromatographic method whereby this study of the pattern of smoke composition and the effect of filters on it can be readily carried out and extended. Gas chromatography has already been widely used on the vapour phase, i. e. that portion of the smoke which will pass through a Cambridge Filter. Much has also been done with

FIGURE I

Compounds measured in themical and spectrophofometric tests

\begin{tabular}{lc}
\hline & Boiling point \\
\hline Nicotine & $247^{\circ} \mathrm{C}$ \\
Phenol (as total phenols) & $182^{\circ} \mathrm{C}$ \\
Acrolein & $52^{\circ} \mathrm{C}$ \\
Hydrogen cyanide & $26^{\circ} \mathrm{C}$ \\
Formaldehyde & $-21^{\circ} \mathrm{C}$ \\
\hline
\end{tabular}




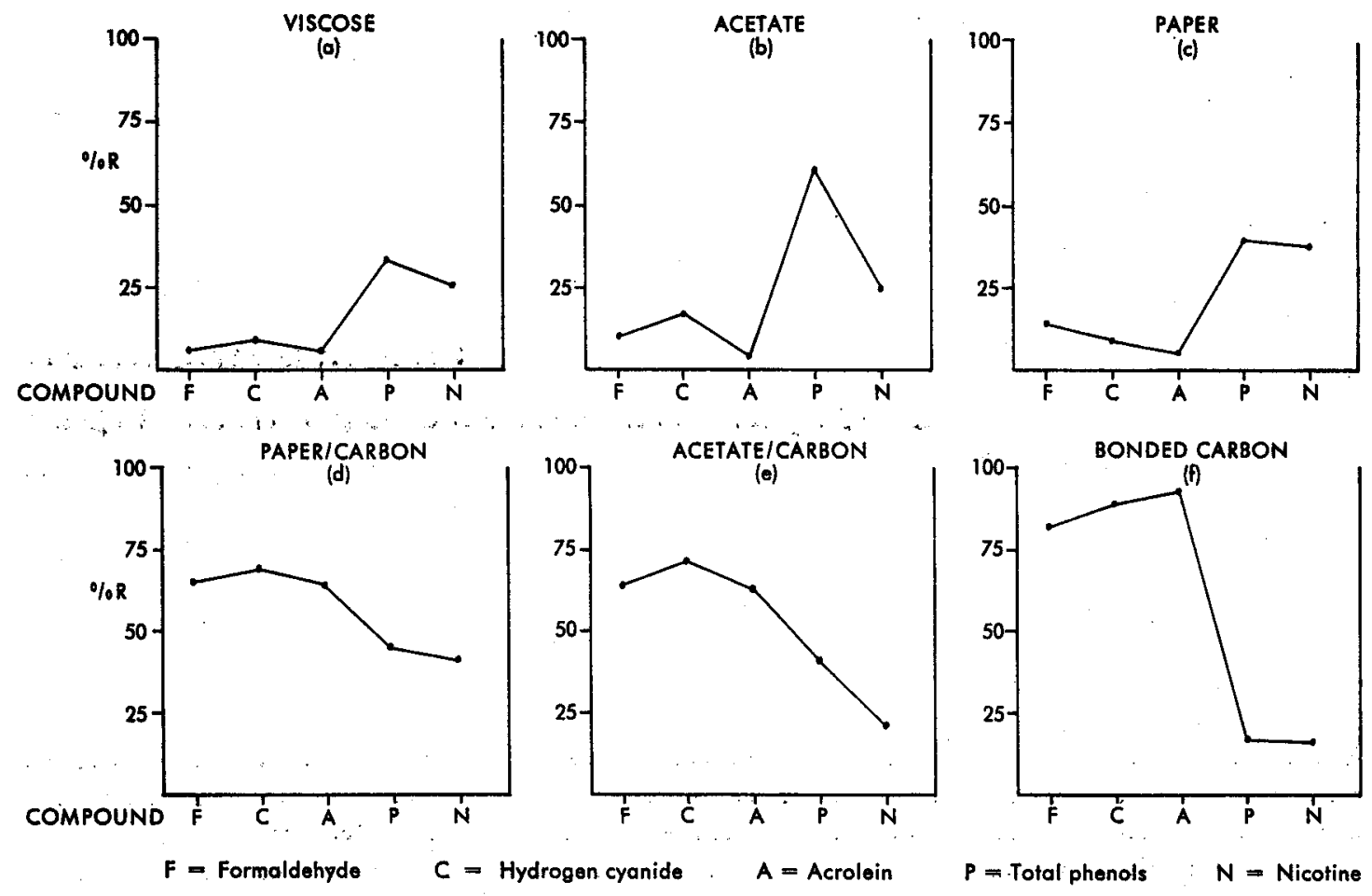

volatile sub-fractions of whole smoke $(6,7,8,9,10,11,12)$ but the particular method we wish to describe has been devised to avoid handling of the smoke and to avoid loss of what we might term semi-volatiles, that is those substances which are retained on a Cambridge Filter but which can be volatilized from it.

The object of this presentation is to make use of the information obtained by the two methods mentioned to examine how a variety of single and dual filters modifies the smoke produced. For this purpose we prepared six basic types of filters and from these we constructed another six combinations of dual filters. As a common point of reference all the filters had the same pressure drop or draw resistance, namely $3.6 \mathrm{~cm}$. W. G. at a flow of $17.5 \mathrm{cc}$. $/ \mathrm{sec}$. (though filters with higher pressure drops are in common use) and all single and dual filters had an overall length of $15 \mathrm{~mm}$.

\section{CHEMICAL AND SPECTROPHOTOMETRIC TESTS}

For the determination of formaldehyde, hydrogen cyanide and acrolein, groups of eight cigarettes were smoked and the portion which passed a Cambridge Filter was collected and assayed for each of the respective compounds by modifications of standard methods quoted in the literature (13, $14,15)$. Due to different processing requirements only one compound could be assayed from each group of eight cigarettes. The efficiency of each type of single or dual filter was determined by running control versus filter cigarettes. Determinations of nicotine and phenol as total phenols were made using the modified Willits method for nicotine, and a colorimetric method based on diazotized p-nitroaniline for phenols, using Cambridge Filters as collection devices. The direct method was used to determine the efficiency of the test filter, that is the amount of phenol and nicotine in the filter tip was determined as well as that retained in the trapping device. In all cases in these and later chromatographic tests, standard English cigarettes cut to $55 \mathrm{~mm}$. lengths were smoked to a $9 \mathrm{~mm}$. tobacco butt using a smoking cycle of $35 \mathrm{ml}$. puff of 2 seconds duration once per minute.

Figures 2 and 3 show in graphical form the pattern of results obtained. We have chosen to use a 

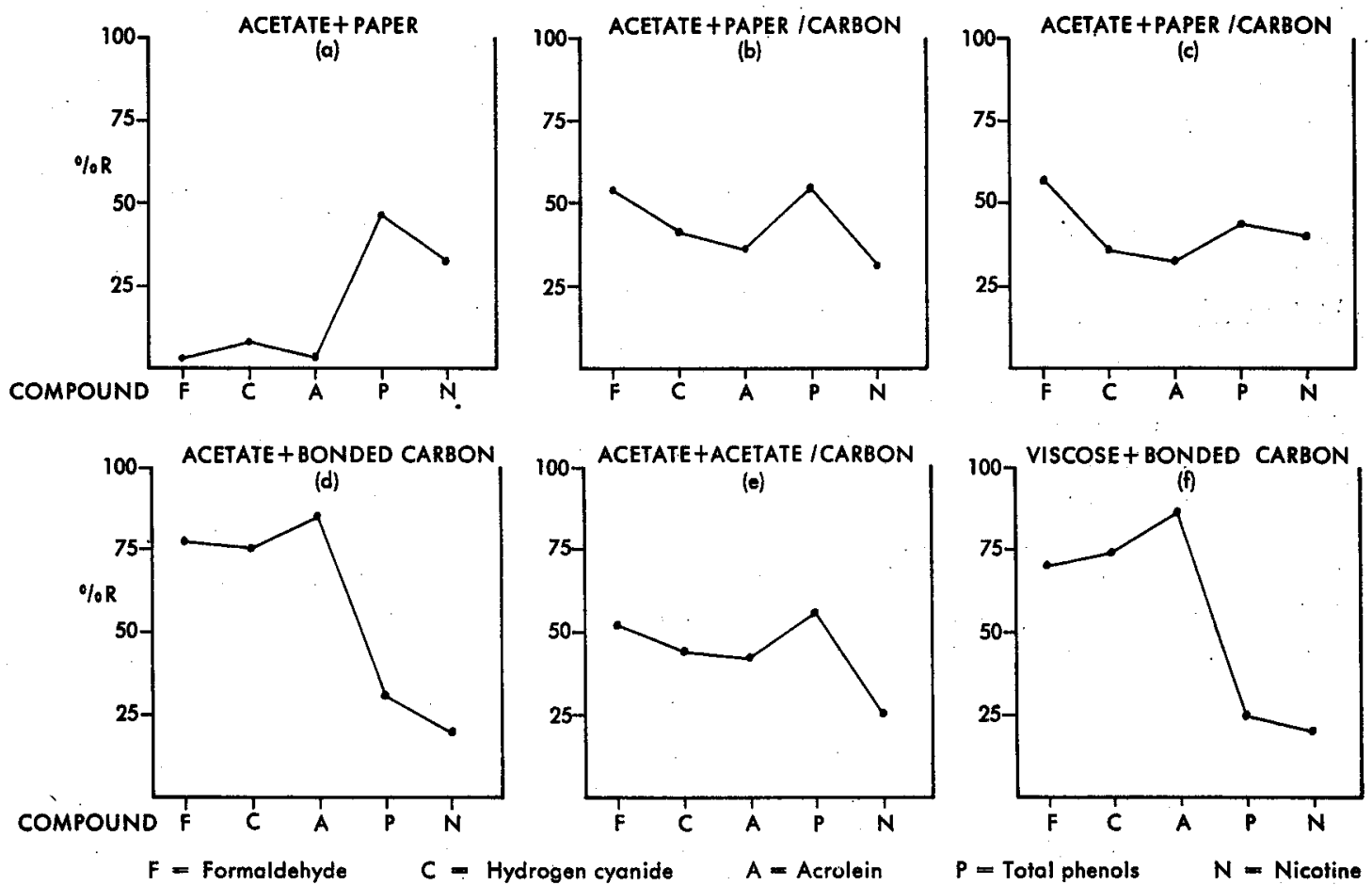

graphical presentation like this to illustrate that the efficiency of a filter varies widely from compound to compound in the smoke. Hence it is to the differences in the pattern obtained from one filter to the next that we wish to draw attention.

Figure 2 shows the six patterns obtained for the six single filters selected. Each pattern is made up of five filtration efficiency results, one for each of the five smoke constituents measured. A cursory glance shows firstly that no two are alike, and that none is a straight horizontal line. A straight horizontal line would be the result obtained by a uniform removal of all the constituents measured. It should be remembered that all these filters have the same pressure drop.

The main observations that can be made are that

1. filters based on cellulose in the form of embossed paper (Figure $2 c$ ) as opposed to either cellulose acetate (Figure $2 \mathrm{~b}$ ) or reconstituted cellulose (Figure $2 \mathrm{a}$ ) in the form of filaments give the best nicotine retention. This applies also when charcoal is added to these bases (Figures $2 \mathrm{~d}$ and e),

2. filters based on cellulose acetate give better phenol retention than the others, this being due to the presence of triacetin which is present as a bonding agent in the acetate filter,

3. carbon filters give the highest removal of the lower boiling constituents such as acrolein, hydrogen cyanide and formaldehyde (Figures $2 \mathrm{~d}$, e and $\mathrm{f}$ ). The non-carbon filters are relatively inefficient towards these compounds.

It is also interesting to see the difference between the three basic carbon types shown. The difference in efficiency towards the higher boiling and lower boiling point compounds is accentuated as we go from carbon on paper (Figure $2 \mathrm{~d}$ ) through carbon on acetate (Figure $2 \mathrm{e}$ ) to carbon alone (Figure $2 \mathrm{f}$ ). The efficiency of the carbon filters towards the low boiling compounds is influenced partly by the amount and type of carbon present and partly by the physical construction of the filter.

Figure 3 shows the patterns obtained from six dual filters made up from selections of the previous six basic filters. A particularly important point to be stressed in connection with these dual filter charts is that some of the combinations of filters shown are non-typical of the actual combinations 
which would be used on commercial cigarettes. In order to have a common reference point in these comparisons we have deliberately constructed all the $7^{1 / 2} \mathrm{~mm}$. filter components used in these dual filters with the same pressure drop, whereas in the case of commercial bonded carbon filters, for example, an outer filter with a higher efficiency for particulate matter would normally be used. This would mean that the phenol and nicotine figures would be much higher in a normal typical dual filter of this type. Figure 3 a shows the effect of combining $7^{1 / 2} \mathrm{~mm}$. lengths of paper and acetate. It will be observed that the nicotine retention of the combination is better than that for acetate alone and the phenol retention is better than that for paper alone. The remaining combinations all include a carbon portion of one type or another. Figures $3 b, c$ and e show the results obtained when non-vapour phase active filters are combined with medium efficiency carbon filters, and each of these three have produced a result which is approaching an equal removal of all the constituents measured. It will be noted again that the paper based filter removes more nicotine while the acetate filter removes more phenol. Figures $3 \mathrm{~d}$ and $f$ shows the result obtained where a non-vapour phase active filter is combined with a high efficiency bonded carbon filter. In this case the overall effect is biased in favour of high volatiles removal and relatively low removal of nicotine and phenol at this P.D. level. In a more typical case of this type of filter the phenol and nicotine retentions would be raised to values of 65 and 45 respectively by increasing the efficiency of the outer non-vapour phase active portion without substantially affecting the vapour phase efficiencies.

\section{TESTS BASED ON GAS CHROMATOGRAPHY}

We now come to the second part of this paper, which describes a new chromatographic method for the examination of the more volatile compounds in the particulate phase of tobacco smoke, and the effect of various filters on their pattern in the smoke. For convenience, we shall refer to this range of compounds, whose boiling points lie between $50^{\circ} \mathrm{C}$ and $250^{\circ} \mathrm{C}$ approximately, as the "semi-volatiles". Also included in this group are the various flavouring agents, humectants and other tobacco and filter additives.

Two special pieces of apparatus have been devised for this work, they are:

\section{An All-Glass Cambridge Filter Unit}

This is shown in Figure 4. The unit is constructed so that the filter pad is held by compression around its edge when the cone and socket are fitted together. The large joint is lubricated with

FIGURE 4 Glass Cambridge Filter unit

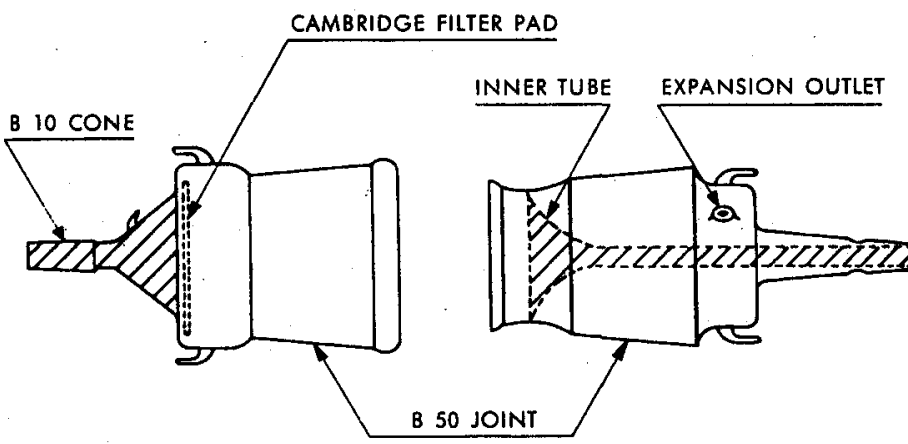
silicone grease and held together by two springs; a narrow tube is sealed inside it to reduce the internal volume. The total volume traversed by smoke is shown by the hatched region.

The cigarette is attached at the B. 10 cone, and after smoking the unit can be transferred to the distillation apparatus without opening it up or disturbing the filter pad, so avoiding any evaporation losses.

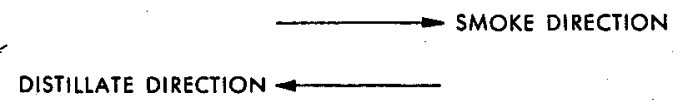

2. A Tube for the Collection, Solution and Sampling of Distillates

The construction is seen in Figure 5, and is basically a narrow bore U-tube, fitted at one end with a wider bore entry tube and B. Io socket for connection to the Cambridge Filter unit, and at the outlet end with a small sampling bulb. The wider bore entry tube prevents blodkage due to condensate freezing when entering the cold zone. The tube permits the solution of distilled 
"semi-volatiles" in a small volume of solvent $(0.5 \mathrm{ml}$ ) and withdrawal of aliquots without loss of the more volatile compounds. The details of the procedure are as follows:

FIGURE 5

Preparation

of "Semi-Volatiles" Solution

Four cigarettes are smoked as before into the glass Cambridge Filter unit (Figure 6). Between cigarettes, the smoke is allowed to settle for 30 seconds before changing the vacuum holder assembly for a fresh one containing the next filter and cigarette. 30 seconds after the smoking has been completed, the last holder and rubber tube are quickly removed and replaced by the receiver $\mathrm{U}$ tube, which has previously been cooled in liquid oxygen. The B. 10 joint is secured with a small spring and the assembly is transferred to the distillation apparatus without delay. The arrangement is shown in Figure 7. The U-tube is placed in a liquid oxygen bath and an argon flow of about $10 \mathrm{ml} / \mathrm{min}$. is applied to the end of the Cambridge Filter unit previously attached to the smoking machine. The Cambridge Filter unit is enclosed in an air oven with the B, 10 joint inside the oven. A flowmeter is connected to the U-tube outlet and liquid oxygen is added to the cold bath so that the level reaches the wider part of the tube. The oven is heated to $180-190^{\circ} \mathrm{C}$, and when this temperature is reached, the argon flow is increased to $25 \mathrm{ml} / /$ minute. After $45 \mathrm{mi}-$ nutes, heating is stopped and the oven opened. When the B. 1o joint is cold, the Cambridge Filter unit is disconnected and $0.5 \mathrm{ml}$. of acetone containing $0.1 \%$ ethyl caproate is added to the U-tube. The ethyl caproate is used as an internal standard for the subsequent procedures. The tube is closed with a B. 10 glass stopper, the flowmeter disconnected and the U-tube withdrawn from the liquid oxygen. After warming the tube
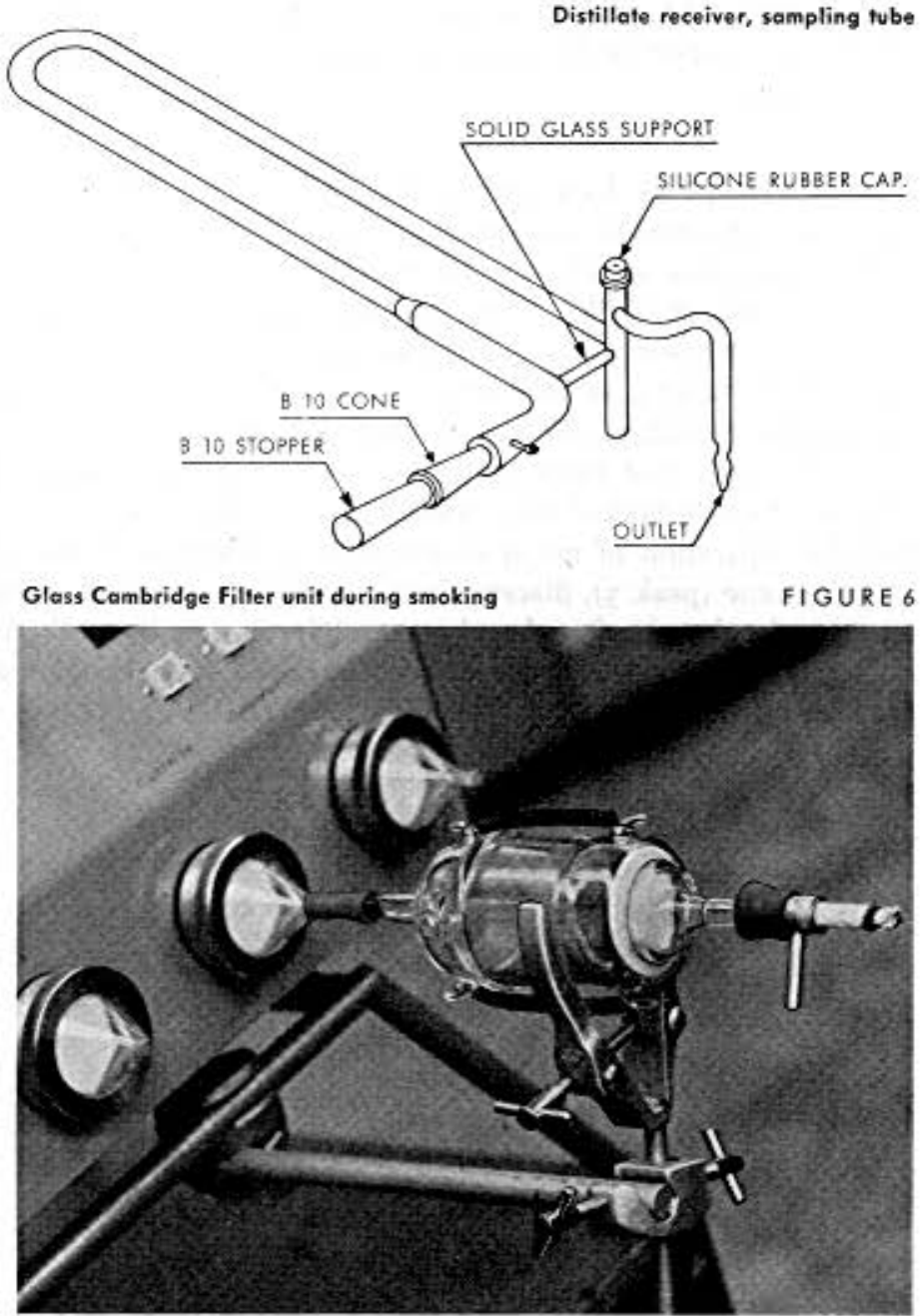

Apperatus connected for distillation of "semi-volatiles"

FIGURE 7

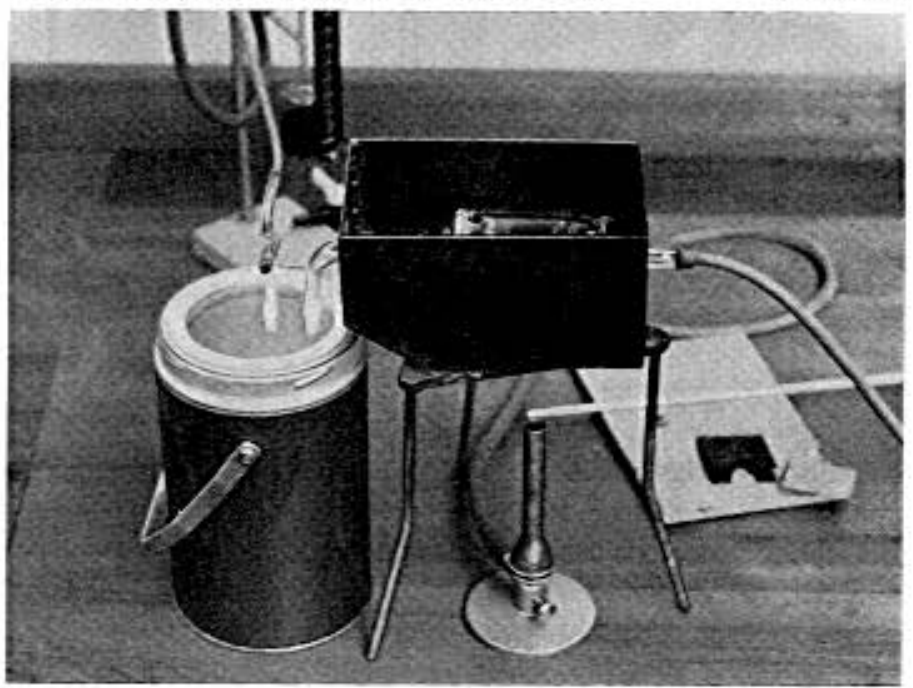


until the contents melt, the outlet end is sealed with a rubber cap. Holding the stopper in firmly, the tube is positioned so that the liquid is all transferred into the wider tubing, with the stopper downward. In this position, the tube can be shaken vigorously to dissolve the condensate and mix the solution. The solution is now transferred to the bulb by turning the tube with gentle tapping. With the solution in the bulb, an aliquot can be withdrawn by syringe via the silicone rubber septum cap.

Chromatography

The instrument we have used is the Perkin-Elmer Model 800 dual column flame ionisation, temperature programmed, gas chromatograph. The columns are $6^{\prime} \times 1 / 4^{\prime \prime}$ copper tubing, packed with $20 \%$ "Carbowax $20 \mathrm{M}^{\prime \prime}$ on "Celite". The carrier gas is nitrogen, flow rate $55 \mathrm{ml} . /$ minute.

A $10 \mu \mathrm{l}$. aliquot of the "semi-volatiles" solution is chromatographed, isothermally at $80^{\circ} \mathrm{C}$ for 5 minutes to clear the solvent peak, then with temperature programming at $3.3^{\circ} \mathrm{C} / \mathrm{min}$. up to $200^{\circ} \mathrm{C}$, continuing at this temperature until no further elution occurs. The time taken is about 70 minutes including column clearing. A typical chromatogram is shown in Figure 8, from which it can be seen that there are more than 40 distinct peaks. The resolving power of the packed columns used is undoubtedly insufficient to give separation of all the compounds actually present, but the separation of major constituents is adequate. Some of these have been identified so far, e. g. benzene (peak 3), diacetyl (peak 4), toluene (peak 8), dipentene (peak 12), furfural (peak 24), nicotine (peak 39), phenol and o-cresol (peak 40), by peak trapping and re-chromatographing on various other columns, together with infra-red spectrophotometry. Other peaks have been tentatively identified and this work is still in progress.

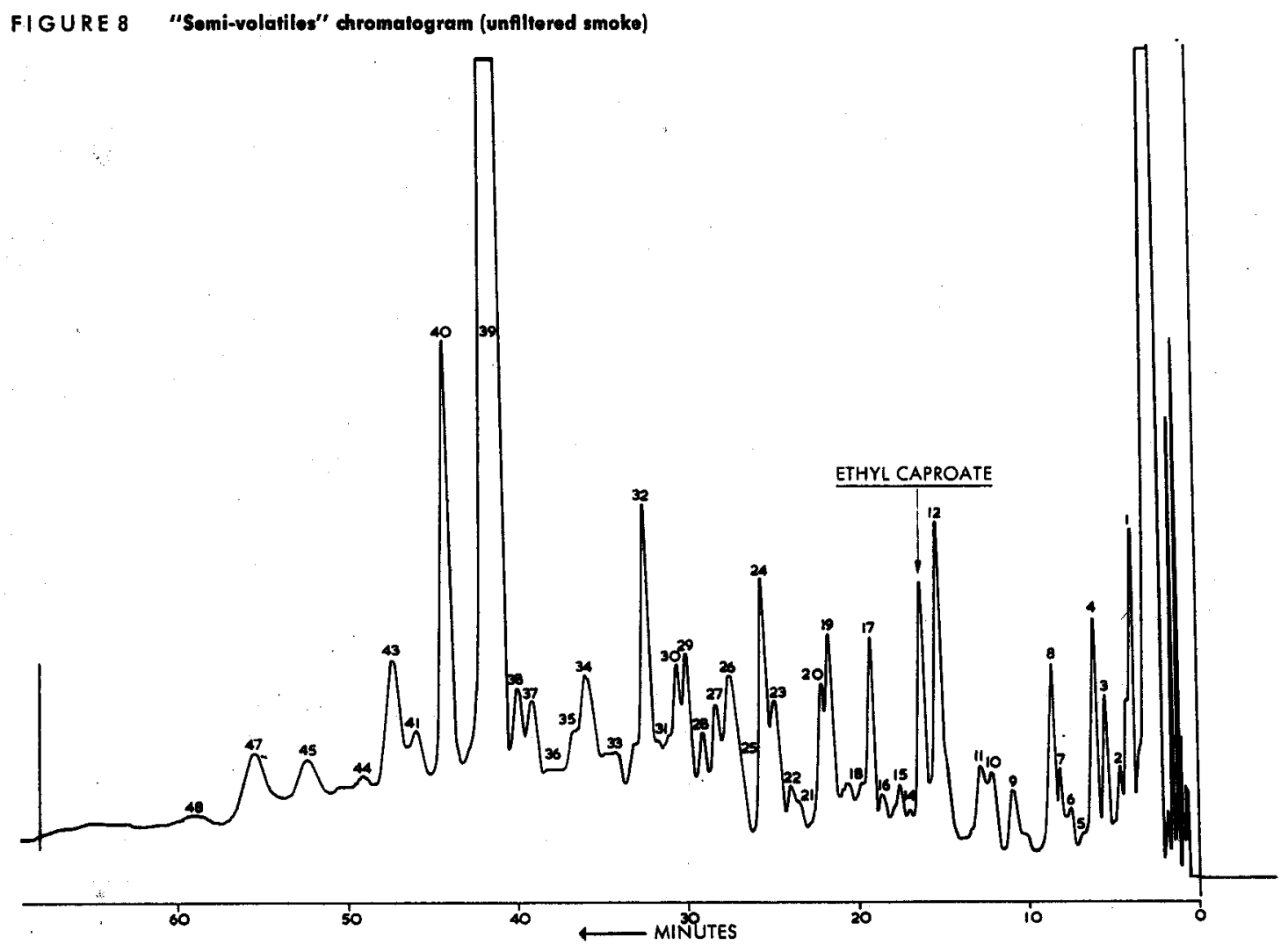

Retention values of filters for several major peaks have been calculated from peak heights by comparison of filtered and unfiltered smoke. Each test was run in duplicate, the control value being the mean of several unfiltered smokes run on different days. Allowance is made for syringe error and day-to-day sensitivity variations by the use of ethyl caproate as internal standard, all peak heights on each chromatogram being correlated to an average peak height for the standard.

The resultant patterns of efficiency for each measured peak number for the six filter types pre- 

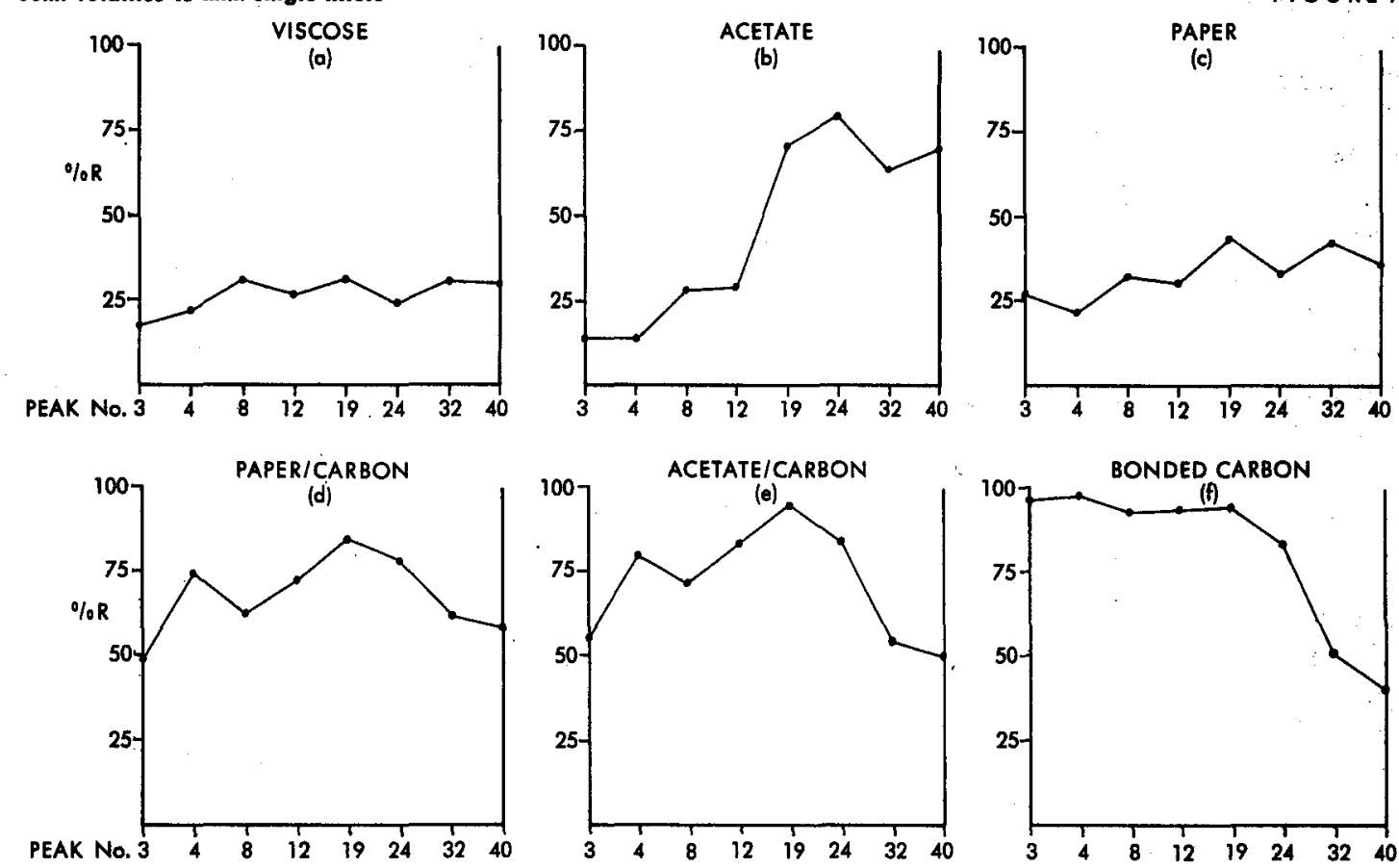

viously discussed are shown in Figure 9. We can expect some of the differences between filters already observed to show up here also; for example, the first few peaks are due to low boiling compounds and they are, therefore, most affected by carbon filters. Total phenols were seen to be retained strongly by acetate, and this is also shown in the last peak, phenol + o-cresol, although there are differences in some cases between the retentions of total phenols and of phenol +o-cresol only. This is due, we feel, to the greater volatility of phenol as opposed to the group "phenols". In the central region of the charts, we have a series of compounds, the retentions of which are also greatly influenced by the type of filter, some being affected by the solvent additive effect as

Somi-volatiles $7.5+7.5 \mathrm{~mm}$. dual filters
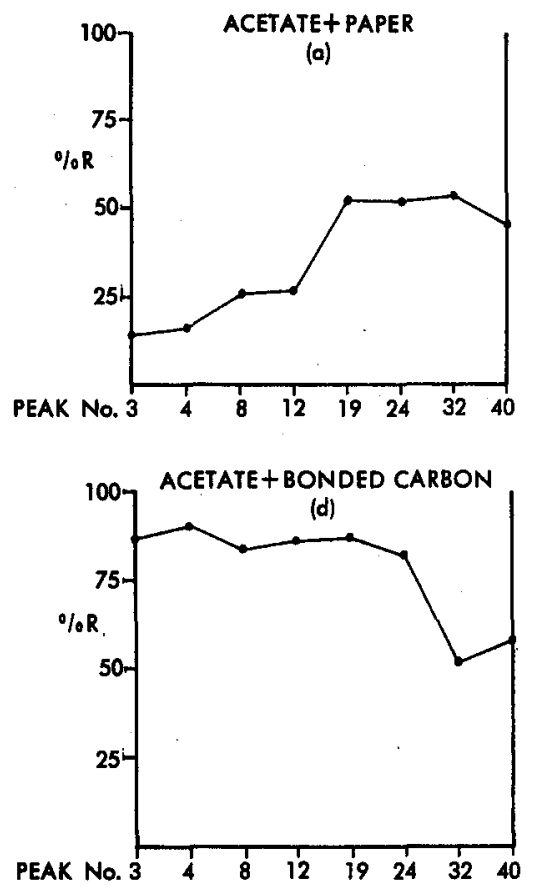
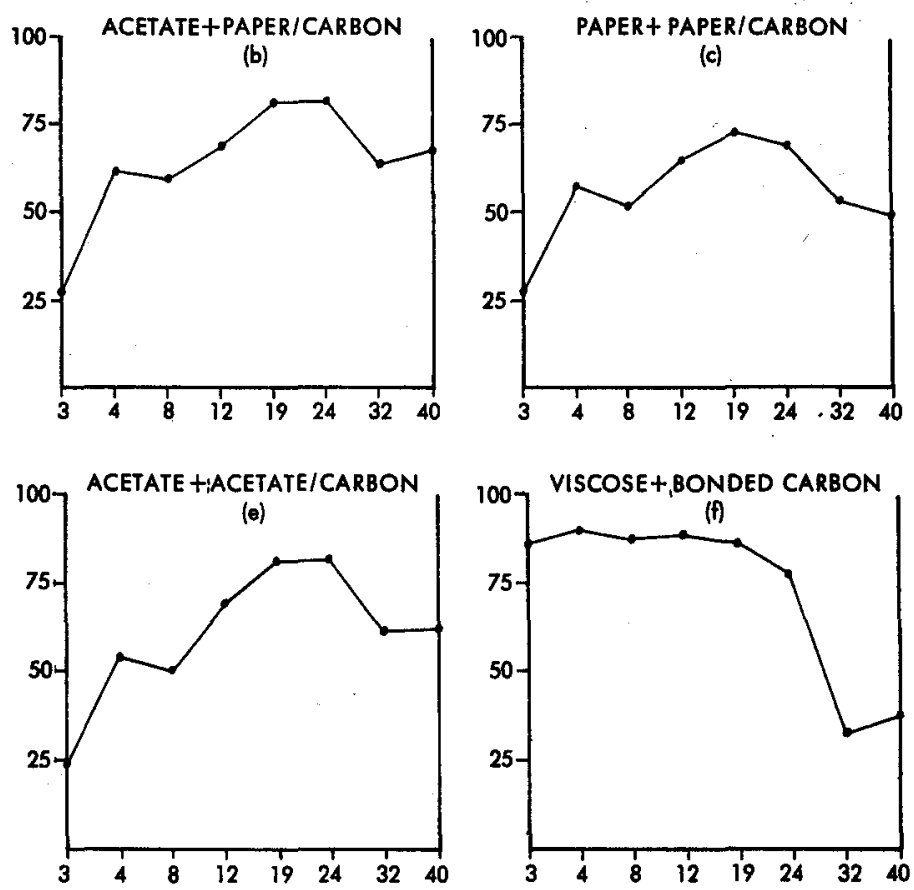
with phenols, others by adsorbents and some by both. In general the group of compounds shown in these charts have boiling points which lie between acrolein and phenol in the first series of charts (Figures 2 and 3 ).

Combinations of the six basic types into dual filters, seen in Figure 10, again shows the variation in result that can be obtained.

These patterns provide us with an over-all picture of the behaviour of a filter towards an important part of the smoke in one operation, rather than building up such a picture from a number of separate determinations. This is useful in assessing ways in which a certain desired filtration effect can be achieved, and in the investigation of the performance of new filter materials and additives. It should be remembered that each filter type mentioned is capable of variation within itself and that the results quoted are for a particular level of pressure drop only. It is planned to extend this investigation by further refinements of the techniques.

\section{THE EXAMINATION OF FLAVOURS, ETC. IN TOBACCO SMOKE}

It was mentioned earlier that flavours, humectants and other additives are found in the "semivolatile" region of the smoke and it is appropriate to include them in the present paper since they affect the composition of the smoke, they can be derived from filters and they can be determined by the chromatographic method described.

For example, the determination of the menthol content of smoke can be made by preparing a solution of the "semi-volatiles" as before, and chromatographing the solution on a $6^{\prime} \times 1 / 4^{\prime \prime}$ mixed column containing 10\% "Carbowax $20 \mathrm{M}^{\prime \prime}$ and $5 \%$ sucrose acetate isobutyrate on "Celite". The temperature is programmed, starting from $100^{\circ} \mathrm{C}$, to $200^{\circ} \mathrm{C}$ at $5^{\circ} \mathrm{C} /$ minute. With a nitrogen carrier gas flow of $55 \mathrm{ml} . /$ minute, menthol is eluted in 17 minutes and the total time is about 40 minutes. Calibration is by injection of standard menthol solutions in the usual way. Interference from normal smoke constituents, humectants, etc. is negligible and in fact the same procedure and columns can be used similarly for the measurement of propylene glycol in tobacco smoke (Figure 11).

In some cases, a preliminary separation of unwanted material in the "semi-volatiles" solution can be effected by the use of a two phase solvent system in the receiver U-tube - nicotine can be removed by an acid/solvent system, or glycols removed by a petroleum ether/water system - the particular conditions of chromatography, time required, solubility, etc. being chosen in each case to obtain the best result.

FIGURE 11

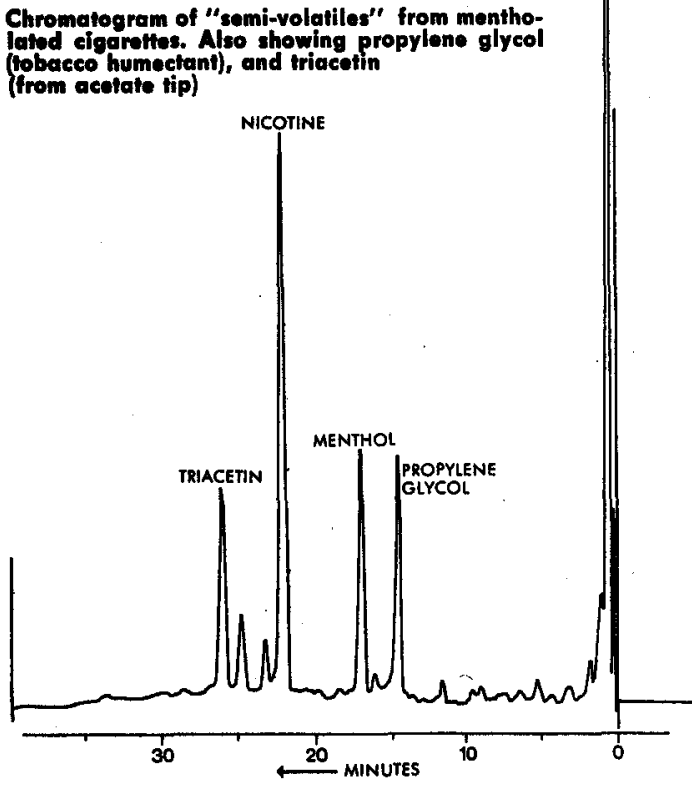

SUMMARY

One of the best known ways of modifying cigarette smoke is by the use of cigarette filters of various types. Filters are now being made from a variety of materials and, of recent years, have become more complex in structure and function. The authors consider the different ways in which different types of filters modify the chemical composition of the smoke showing some typical results. A new method of studying the range of higher boiling compounds in the smoke based on the volatilization of compounds trapped on a Cambridge Filter is discussed and information which this provides with different filter types is presented. Having shown the different action of the available range of filters as individuals, the possibilities of combining these in different ways to produce multiple filters and the degree of control of the smoke composition made possible as a 
result are discussed. If one examines the efficiency of any type of filter towards the whole range of substances in tobacco smoke from the permanent gases up to the high boiling compounds such as nicotine, one finds that the efficiency of the same filter varies widely according to the compound considered. Further, one finds that the pattern of efficiencies over the range of compounds is quite different between one filter and another. If, in the design of a filter cigarette, one wishes to emphasize or reduce various portions of the smoke it is possible to exercise a considerable degree of control by the use of suitable types of filter or combinations of filters. In addition to removing smoke constituents to varying degrees it is also possible to add desirable constituents to the smoke such as flavours by means of filters and the analytical technique mentioned above is very suitable for assessing the amount of such flavouring material which is actually present in the cigarette smoke.

ZUSAMMENFASSUNG

Eines der bekanntesten Mittel, durch das der Rauch von Cigaretten verändert werden kann, ist die Verwendung verschiedener Sorten von Cigarettenfiltern. Gegenwärtig werden Filter aus einer Reihe verschiedenartiger Stoffe hergestellt. Konstruktion und Funktion der Filter sind im Laufe der letzten Jahre komplizierter geworden. Die Autoren untersuchen die verschiedenen Vorgänge, durch die die einzelnen Filtertypen die chemische Zusammensetzung des Rauches ändern und geben einige charakteristische Resultate an. Es wird eine neue Methode zur Untersuchung der im Rauch enthaltenen Verbindungen mit höherem Siedepunkt diskutiert, die auf dem Prinzip der Verflüchtigung der im Cambridge-Filter aufgefangenen Verbindungen beruht, und es wird dargelegt, zu welchen Ergebnissen diese Methode bei verschiedenen Filterarten führt. Nach Beschreibung der jeweiligen Wirkungsweise der einzelnen Filter wird die Möglichkeit diskutiert, Filter auf verschiedene Weise zu kombinieren und so Mehrfach-Filter herzustellen. Das Ausmaß der dadurch ermöglichten Beeinflussung der Rauchzusammensetzung wird diskutiert. Die Untersuchung der. Wirksamkeit eines Filters gegenüber allen im Tabakrauch enthaltenen Substanzen - von den permanenten Gasen bis zu den Verbindungen mit hohem Siedepunkt (z. B. Nikotin) - zeigt, daß eir Filter auf verschiedene Verbindungen sehr unterschiedlich wirkt. Weiterhin ist erkennbar, daß die Wirkungsmechanismen der verschiedenen Filter gegenüber einer bestimmten Substanz sehr unterschiedlich sind. Wenn bei der Herstellung einer Filtercigarette beabsichtigt ist, bestimmte Rauchbestandteile hervortreten zu lassen oder zu vermindern, so ist es durchaus möglich, durch Verwendung entsprechender Filterarten oder. Filterkombinationen eine weitgehende Steuerung zu erreichen. Durch die Verwendung von Filtern ist es möglich, Bestandteile des Rauches in verschiedenem Ausmaß zu entfernen wie auch dem Rauch erwünschte Bestandteile, wie z. B. Aromastoffe, hinzuzufügen. Der Gehalt des Cigarettenrauches an solchen Aromastoffen läßt sich mit dem oben erwähnten analytischen Verfahren sehr gut ermitteln.

RESUME

Un des moyens les mieux connus de modifier la fumée de la cigarette est l'emploi de boutsfiltres de divers types. On fait à présent des filtres avec des substances variées et ils sont devenus ces dernières années plus complexes par leur structure et leur fonction. Les auteurs examinent les différents processus par lesquels des filtres différents modifient la composition chimique de la fumée et présentent quelques résultats typiques. On discute une nouvelle méthode d'étude de la gamme des composés de la fumée à point d'ébullition élevé, basée sur la volatilisation des composés piègés sur un filtre Cambridge et on présente l'information qu'elle fournit pour différents types de filtres. Après avoir montré l'action individuelle de chacun des filtres de la gamme dont on dispose, on discute des possibilités de les combiner de façons diverses pour produire des filtres multiples et des possibilités qui en résultent pour contrôler la composition de la fumée. Si on examine l'efficacité d'un type de filtre vis-à-vis de la gamme totale des composants de la fumée du tabac, depuis les gaz permanents jusqu'aux composés à point d'ébullition élevé, tels que la nicotine, on trouve que l'efficacité du même filtre varie beaucoup suivant le composant considéré. En outre, on trouve que le mécanisme des efficacités vis-à-vis de la gamme des composants est très différent d'un filtre à l'autre. $\mathrm{Si}$, lors de l'élaboration d'un filtre à cigarette on désire mettre en évidence, ou réduire, diverses portions de la fumée, il est possible d'intervenir de façon 
importante en utilisant des types convenables de filtre ou de combinaisons de filtres. Outre l'élimination plus ou moins complète de constituants de la fumée il est également possible d'ajouter à la fumée des constituants désirables tels que des aromatisants au moyen des filtres et la technique analytique mentionnée ci-dessus convient bien pour estimer la quantité de substances aromatisantes qui est réellement présente dans la fumée de la cigarette.

REFERENCES

1. Hoffmann, D., and Wynder, E. L.: J. Nat. Cancer Inst. 30 (1963) 67.

2. Irby, R. M., and Harlow, E. S.: Tobacco Science 3 (1959) 52.

3. Norman, V., Newsome, J. R., and Keith, C. H.: I7th Tob. Chem. Res. Conf., Montreal, Quebec, 1963; Inf. Bull. Coresta 1963-4, Abstr. 7728.

4. Williamson, J. T., Allman, D. R., and Houlan, K. G.: 16th Tob. Chem. Conf., Richmond, Va., 1962; Inf. Bull. Coresta 1962-4, Abstr. 6544.

5. Williamson, J. T., and Allman, D. R.: Inf. Bull. Coresta 1964-1, pp. 7-17.

6. Stedman, R. L.: Inf. Bull. Coresta 1963-4, pp. 11-27.

7. Johnstone, R. A. W., Quan, P. M., and Carruthers, W.: Nature 195 (1962) 1267.

8. Quin, L. D.: J. Org. Chem. 24 (1959) 911-916.

9. (i) Spears, A. W.: Anal. Chem. 35 (1963) 320,

(ii) Spears, A. W.: Tob. Sci. 7 (1963) 76.

10. Mitchell, B. C., Barbee, E. P., and Irby, R. M.: Tob. Sci. 7 (1963) 64.

11. Guvernator, G. C.: Tob. Sci. 7 (1963) 63.

12. Hoffmann, D., and Wynder, E. L.: Beitr. z. Tabakforschg. I (1961) 101.

13. Ryan, J. A., and Culshaw, G. W.: Analyst 69 (1944) 370.

14. Cohen, I. R., and Altshuller, A. P.: Anal. Chem. 33 (1961) 726.

15. Boyd, J. M., and Logan, M. A.: J. Biol. Chem. 146 (1942) 279.

The authors' address:

Cigarette Components Ltd., Friendly House, 21-24 Chiswell Street, London E. C. 1, England 